\title{
Dispersion chart for some popular distributions under repetitive sampling
}

\author{
Liaquat AHMAD*, Muhammad ASLAM**, Arif, O.H** and Chi-Hyuck JUN*** \\ *Department of Statistics and computer Science, University of Veterinary and Animal Sciences \\ Lahore 54000, Pakistan \\ ${ }^{* *}$ Department of Statistics, Faculty of Sciences, King Abdulaziz University \\ Jeddah 21551, Saudi Arabia \\ E-mail: aslam_ravian@hotmail.com \\ ***Department of Industrial and Management Engineering \\ POSTECH, Pohang 790-784, Republic of Korea
}

Received 23 February 2016

\begin{abstract}
A control chart is an important tool of the statistical process control for monitoring deviations from a stable production process. For this purpose different control schemes have been developed for the fast detection of certain changes in the process parameters. We reconsider the recently proposed exponentially weighted moving average (EWMA) chart based on the mean absolute deviation from the median (called EWMA-MD chart) to monitor the process variation. The repetitive group sampling scheme through two pairs of control limits has been incorporated in the proposed control chart to enhance the performance. The performance of the proposed control chart is evaluated in terms of the average run length through simulation when the quality characteristic of interest follows a normal distribution, a gamma distribution or a t-distribution. The results show better detecting ability of the proposed control chart as compared with the existing EWMA-MD chart for small to moderate shifts in the process dispersion.
\end{abstract}

Key words: Control chart, Exponentially weighted moving average, Repetitive group sampling, Average run length, Monte Carlo simulation, Process dispersion

\section{Introduction}

A control chart is an important tool of the statistical process control to monitor any change in the quality characteristic of the on-line process. Shewhart (1926) introduced the concept of control limits for the monitoring of the process mean (X-bar chart) and dispersion (R or S- chart). A chart considering only the process mean shift may lead to an erroneous decision when it is related to a shift in the process dispersion. The traditional X-bar and $\mathrm{R}$ charts are considered to be less efficient in detecting the small shifts in the process parameters of the quality characteristics due to the memoryless nature of the statistics.

Roberts (1959) proposed a control chart procedure for the fast detection of small shifts in the process mean, which is called an exponentially weighted moving average (EWMA) control chart. Another control chart, called CUSUM chart, utilizing the cumulative sum (CUSUM) was proposed by (Page, 1954) and is popularly used for detecting small shifts in the process mean.

Traditional control charts are based on the current information whereas the EWMA charts use the current as well as the past information by incorporating a varying weight scheme: more weight is assigned to the latest observation and the weights are decreased exponentially to the past values. Its properties have been thoroughly investigated by (Srivastava \& Wu, 1993). An EWMA chart is not only as simple to apply as the CUSUM, but it can be used to monitor a shift in either direction as compared to CUSUM scheme. The EWMA charts for monitoring mean have been explored by many authors including (Borror, Montgomery, \& Runger, 1999; Robinson \& Ho, 1978; Shamsuzzaman, Khoo, Haridy, \& Alsyouf, 2014). The multivariate EWMA control charts for monitoring multivariate mean vector have been explored by many authors including (Stoumbos \& Sullivan, 2002) ; (Testik, 
Runger, \& Borror, 2003) and Fallah Nezhad (2012).

Monitoring dispersion of the process using the EWMA chart has attracted many researchers since the last decade. See, for example, (Chan \& Zhang, 2000), (Stoumbos \& Reynolds, 2000), (Maravelakis, Panaretos, \& Psarakis, 2005), (Park, Moon, Jun, Balamurali, \& Lee, 2004), (Abbasi, 2010) and (Abbasi \& Miller, 2013).

This study proposes a new EWMA chart using the mean absolute deviation from median (MADM) as suggested by (Abbasi \& Miller, 2013) which is based upon the conventional single sampling scheme but we developed the control chart under the repetitive group sampling scheme in order to diagnose a shift quickly in the process dispersion. The repetitive group sampling (RGS) scheme was first introduced by (Sherman, 1965) when he proposed an attribute acceptance sampling plan. Sherman (1965) concluded that its efficiency is intermediate between single sampling seheme and the sequential probability ratio (SPR) sampling scheme and that the SPR sampling scheme is cumbersome to interpret as compared to the RGS scheme. The RGS scheme is quite popular in the literature of the quality control see, for example, (Balamurali \& Jun, 2006), (Balamurali, Park, Jun, Kim, \& Lee, 2005), (Muhammad Aslam, Yen, \& Jun, 2011), and (M. Aslam, Niaki, Rasool, \& Fallahnezhad, 2012). Recently, (Ahmad, Aslam, \& Jun, 2014b) have studied the X-bar control chart using the process capability index under the RGS scheme and concluded that this sampling scheme is efficient in detecting out-of-control process quickly when the quality characteristics under study are normally distributed. The scheme of RGS has been applied in a practical situation by(Ahmad, Aslam, \& Jun, 2014a).

The novelty of this article is to propose a more flexible control chart to include the existing ones for monitoring the process dispersion by incorporating the RGS scheme. The rest of this paper is organized as follows: the proposed EWMA chart using RGS scheme for dispersion has been given in Section 2. The measure of dispersion, the median absolute deviation from median (MADM) is also described in Section 2. In Section 3, the performance evaluation of the proposed control chart in terms of the average run length is carried out through the Monte Carlo simulation. Comparison of the proposed control chart to the existing EWMA-MD chart has been discussed in Section 4. Finally, in Section 5, concluding remarks have been given.

\section{Proposed EWMA control chart}

The range chart (R-Chart) and the standard deviation chart (S-Chart) are the most commonly used dispersion charts in the literature of quality control. The R-Chart is the simplest chart based on the statistic $\mathrm{R}$ defined as $\mathrm{R}=$ $\mathrm{X}_{\max }-\mathrm{X}_{\min }$. This measure uses the two extreme values in the data set and neglects the remaining values resulting in losing the efficiency when the sample size is increased. On the other hand, the use of standard deviation (which is considered as the very much sensitive to the presence of outliers in the observations) in control chart domain has been criticized by many authors. Eddington (1914) criticized the use of standard deviation as a measure of dispersion. Tukey (1960) also criticized the use of standard deviation and reached the same conclusion as described by (Eddington, 1914).

According to (Gorard, 2004), the concept of standard deviation is rather difficult and complex to understand as compared to the mean absolute deviation from median (MADM or MD), which is defined for a sample of size $\mathrm{n}$ by

$$
\mathrm{MD}=\frac{1}{\mathrm{n}} \sum_{\mathrm{i}=1}^{\mathrm{n}}\left|\mathrm{X}_{\mathrm{i}}-\widetilde{\mathrm{X}}\right|
$$

where $X_{\mathrm{i}}$ 's are observations in the sample and $\widetilde{\mathrm{X}}$ is the sample median. The equation of the EWMA statistic is

$$
\mathrm{W}_{\mathrm{t}}=\lambda \mathrm{MD}_{\mathrm{t}}+(1-\lambda) \mathrm{W}_{\mathrm{t}-1}
$$

where $\lambda$ is the EWMA weighting parameter ranging from 0 to $1, W_{0}=\overline{\mathrm{MD}}$ and $\mathrm{W}_{\mathrm{t}}$ is the statistic posted on the control chart.

Leys, Ley, Klein, Bernard, and Licata (2013) advocated the use of the MADM instead of the conventional standard deviation for the detection of outliers in the data set. The use of dispersion control chart using the mean of 
the absolute deviations from median has been suggested by many authors. Riaz and Saghir (2009) advocated that the use of MADM is superior to the $\mathrm{R}$ chart and the $\mathrm{S}$ chart.

The proposed EWMA control chart has double control limits (outer control limits denoted by $\mathrm{UCL}_{1}$ and $\mathrm{LCL}_{1}$ as well as inner control limits denoted by $\mathrm{UCL}_{2}$ and $\mathrm{LCL}_{2}$ ). If the plotted statistic is located outside of the outer control limits, the process is declared as out-of-control, while in-control is declared if the statistic is inside the inner control limits. When the plotted statistic is located between the inner and outer control limits, decision is postponed and resampling is performed.

The procedure of the proposed EWMA control chart based on MADM under repetitive sampling is as follows:

Step-1: Select a random sample of size $\mathrm{n}$ from the production process and calculate sample mean absolute deviation from median $(\mathrm{MADM}), \mathrm{MD}_{\mathrm{t}}=\frac{1}{\mathrm{n}} \sum_{\mathrm{i}=1}^{\mathrm{n}}\left|\mathrm{X}_{\mathrm{i}}-\widetilde{\mathrm{X}}\right|$ where $\widetilde{\mathrm{X}}$ is the sample median and calculate the EWMA statistic $\mathrm{W}_{\mathrm{t}}=\lambda \mathrm{MD}_{\mathrm{t}}+(1-\lambda) \mathrm{W}_{\mathrm{t}-1}$ for a smoothing constant $\lambda$

Step-2: We shall declare out-of-control if $\mathrm{W}_{\mathrm{t}} \geq \mathrm{UCL}_{1}$ or $\mathrm{W}_{\mathrm{t}} \leq \mathrm{LCL}_{1}$ and in-control if $\mathrm{LCL}_{2} \leq \mathrm{W}_{\mathrm{t}} \leq \mathrm{UCL}_{2}$. Otherwise, go to step-1 and repeat the process.

Under the proposed control chart, the control limits are given as follows:

$$
\begin{aligned}
& \mathrm{UCL}_{1}=\overline{\mathrm{W}}+\mathrm{k}_{1} \mathrm{~s}_{\mathrm{W}} \\
& \mathrm{LCL}_{1}=\overline{\mathrm{W}}-\mathrm{k}_{1} \mathrm{~s}_{\mathrm{W}} \\
& \mathrm{UCL}_{2}=\overline{\mathrm{W}}+\mathrm{k}_{2} \mathrm{~s}_{\mathrm{W}} \\
& \mathrm{LCL}_{2}=\overline{\mathrm{W}}-\mathrm{k}_{2} \mathrm{~s}_{\mathrm{W}}
\end{aligned}
$$

In the above, $\overline{\mathrm{W}}$ and $\mathrm{s}_{\mathrm{W}}$ are the sample mean and the standard deviation of the preliminary sample, respectively, from an in-control process. We have two control constants $\mathrm{k}_{1}$ and $\mathrm{k}_{2}$.

The monitored EWMA statistic is required to be sensitive to changes in the underlying process. The sensitive statistics $\mathrm{W}_{\mathrm{t}}$ of the above mentioned equation with $\mathrm{W}_{0}=\overline{\mathrm{MD}}$ are plotted on a chart with center line $\overline{\mathrm{W}}_{\mathrm{t}}$ and control limits $\mathrm{UCL}_{2}$ and $\mathrm{UCL}_{1}$. The proposed control chart is defined in a way to study only the upward shifts (increase in the process dispersion as decrease in the process dispersion is an indication of the process improvement) and therefore we required only the $\mathrm{UCL}_{1}$ and $\mathrm{UCL}_{2}$. The statistic for the chart defines the area between central line and the $\mathrm{UCL}_{2}$ being in-control process (Ahmad et al., 2014b).

\section{Performance Evaluation}

The performance of a control chart for detecting a shift in the process can be measured by the average run length, which is the expected number of samples required before the chart signals. Larger ARL values are desirable under the in-control process, whereas smaller ARLs under out-of-control process are better so that we are quickly informed that the process has shifted. The use of ARLs for the process evaluation have been criticized by many authors including (Barnard, 1959; Bissell, 1969; F. Gan, 1994; F. F. Gan, 1993; Woodall, 1983) as it produces the misleading results when the run length distribution is skewed or if it follows a non-normal distribution or the form of the distribution is unknown. An alternative measure that is more reliable and acceptable is the median of the run length distribution (MDRL) (Abbasi \& Miller, 2013; Maravelakis et al., 2005). Usually the standard deviation of the run length distribution (SDRL) is estimated whenever the average run length is calculated (Abbasi \& Miller, 2013; Maravelakis et al., 2005). In this article we used these three measures i.e. ARL, MDRL and SDRL for the thorough behavior of the proposed control chart in early detecting of the out-of-control process.

We want a false alarm with probability smaller than $\alpha$ (type I error) and an out-of-control signal with probability at least $1-\beta$ ( $\beta$ refers to type II error) whenever the process shifts. Since the number of samples until a signal follows a geometric distribution, so we have 


$$
\begin{aligned}
& \mathrm{ARL}_{0}=1 / \alpha \\
& \text { and } \mathrm{ARL}_{1}=1 /(1-\beta)
\end{aligned}
$$

The distribution of the control statistic is difficult to derive so the Monte Carlo simulation procedure is used for evaluating these ARLs.

We will consider various cases for the distribution of the quality characteristic. Suppose that the quality characteristic under study has a normal distribution with the location parameter $\mu$ and the scale parameter $\sigma$. Then, the density function $\phi(\mathrm{x} ; \mu, \sigma)$ of a normal distribution is

$$
\mathrm{N}(\mathrm{x} ; \mu, \sigma)=\phi(\mathrm{x} ; \mu, \sigma)=(1 / \sigma \sqrt{2 \pi}) \exp \left(-(\mathrm{x}-\mu)^{2} / 2 \sigma^{2}\right), \quad-\infty<x<\infty
$$

In real life situation, the assumptions of the normally distributed quality characteristic are either not known or never met so, two other distributions i.e. the heavy tailed symmetrical Student's t-distribution and the positively skewed gamma distribution are also considered in this study. Their probability distributions are given as

$$
\begin{array}{cc}
\mathrm{t}(\mathrm{x} ; v)=\phi(\mathrm{x} ; v)=\frac{\Gamma\left(\frac{v+1}{2}\right)}{\sqrt{v * \pi} \Gamma(v / 2)}\left(1+\frac{\mathrm{x}^{2}}{v}\right)^{-\left(\frac{v+1}{2}\right)}, & -\infty<x<\infty, v>0 \\
\operatorname{Gamma}(\mathrm{x} ; \alpha, \beta)=\Phi(\mathrm{x} ; \alpha, \beta)=\frac{\beta^{\alpha}}{\Gamma(\alpha)} \mathrm{x}^{\alpha-1} \mathrm{e}^{-\beta \mathrm{x}}, & \mathrm{x}>0
\end{array}
$$

The Monte Carlo simulation procedure is as follows(Abujiya, Lee, \& Riaz, 2014):

3.1. (Sample mean and variance of control statistic)

3.1.1 Generate a random sample of size $n$ at each subgroup (we used a sample of size $n=5,10$ or 15 as given in Tables 1, 3 and 5) from a selected distribution having the specified parameters for in-control process. Generate 1,000 such subgroups. Any of the sample size can be used but we used the same values as suggested by Abbasi and Miller (2013) in order to maintain similarity for the purpose of comparison.

\subsubsection{Calculate $\mathrm{W}_{\mathrm{t}}$ for each subgroup.}

3.1.3 Calculate $\overline{\mathrm{W}}$ and $\mathrm{s}_{\mathrm{W}}$ from 1,000 subgroups.

3.2. (Setting up control limits)

3.2.1 Select the initial values of $\mathrm{k}_{1}$ and $\mathrm{k}_{2}$.

3.2.2 Generate a random variable at each subgroup from the selected distribution having the specified parameters for in-control process.

3.2.3 Calculate $\mathrm{W}_{\mathrm{t}}$ for $\mathrm{t}$-th subgroup.

3.2.4 Follow the procedure of the proposed control chart and check if the process is declared as out-of-control. If the process is declared as in-control, go to Step 3.2.5. If the process is declared as out-of-control, record the number of subgroups so far as the in-control run length.

3.2.5 Repeat Steps 3.2.2 through 3.2.4 a sufficient number (10,000 say) of times to calculate the in-control ARL. If the in-control ARL is equal to the specified $\mathrm{ARL}_{0}$, then go to Step 3.3 with the current values of $\mathrm{k}_{1}$ and $\mathrm{k}_{2}$. Otherwise, modify the values of $\mathrm{k}_{1}$ and $\mathrm{k}_{2}$ and repeat Steps 3.2.2 to 3.2.5.

\section{3. (Evaluating the out-of-control ARL)}


3.3.1 Generate a random sample of size $\mathrm{n}$ for a subgroup from the selected distribution considering a process shift.

3.3.2 Calculate $\mathrm{W}_{\mathrm{t}}$ for $\mathrm{t}$-th subgroup.

3.3.3 Repeat 3.3.1 and 3.3.2 until the process is declared as out-of-control. Record the number of subgroups until this as a run length (Kane, 1986).

3.3.4 Repeat the above steps 10,000 times to obtain the ARL.

In the simulation study, we consider the three distributions as $\mathrm{N}(\mathrm{x} ; 0,1), \mathrm{t}(\mathrm{x} ; 5)$ and Gamma( $\mathrm{x} ; 2,1)$. Here, the shifts in the variance of the process are considered. For the normal distribution, for example, the shifted standard deviation will be

$$
\sigma_{1}=\delta \sigma_{0}
$$

where $\sigma_{0}$ is the standard deviation of the process that is in control and $\sigma_{1}$ is the one for the shifted process, $\delta$ is the shift constant ranging from 1.0 to 2.0 . Note that $\delta=1.0$ indicates the in-control process.

Using the above procedure, we presented the ARL, MDRL and SDRL for the three distributions for various values of sample size $n, \lambda$ and shifts $\delta$. In Table 1, these values are reported for the normal distribtuion. In Table 2, we present these charactertics for $n=5$ and various values of $\lambda$. In Tables 3-4, we reported these characterictcs for $t-$ distribution and in Table 5 for gammad distribution.

Tables 1-5 are around here

From these tables, we note that there is decreasing trend in ARL, MDRL and SDRL as we note the increasing trend in $\delta$. For $\delta=1$, the values of $\mathrm{ARL}_{1}$ is same as $\mathrm{r}_{0}$, where $\mathrm{r}_{0}$ is specified ARL.

\section{Comparison of the proposed control charts with existing ones}

In this section, we will compare the performance of the proposed control chart with (Abbasi \& Miller, 2013). For the comparisons purpose, we selected the same distributions as given in (Abbasi \& Miller, 2013). Further, for the comparison purpose, we will select the same values for two control charts. To save the space of the paper, we make the diagrams. In Fig. 1, we can see the comparison of the proposed control chart with (Abbasi \& Miller, 2013) for the normal distribution when $\mathrm{n}=5$ and $\lambda=0.25$. We can see that $\mathrm{ARL}_{1}$ curve of the existing control chart is higher than the proposed control chart. Figures 1-3 show the comparison of the proposed and the existing chart for different settings of the parameters which portray the better detecting ability of the proposed scheme under the normal distribution. Figures 4-5 show the comparison of the proposed control chart with the existing control chart for t-distribution. Once again, the performance of the proposed control chart is excellent as compare to the existing control chart.

Figures 1-5 are around here

Table 6 is around here

Table 6 shows the comparison of the proposed control chart with the existing for the gamma distribution for same values of all specified parameters. We note from the table that the proposed control chart performs better than the existing control chart for gamma distribution too.

\section{Illustrative Examples}




\section{Example 1}

To use the proposed control chart in real word problems, we will consider the data given in Montgomery (2009), Table 6.2 on page 236 of flow width measurements (microns) of wafers from the hard-bake process. Using the coefficients values of $\mathrm{k}_{1}=2.325424$ and $\mathrm{k}_{2}=1.481746$ for $\mathrm{n}=5$ under the normal distribution. The four control limits have been calculated as $\mathrm{UCL}_{1}=0.091138, \mathrm{UCL}_{2}=0.089769, \mathrm{LCL}_{2}=0.084958, \mathrm{LCL}_{1}=0.083588$. For the purpose of comparison with the single sampling scheme, Figures 7 and 9 have been drawn using the control limits $\mathrm{UCL}=0.091323$ and $\mathrm{LCL}=0.083404$ using the control chart parameters proposed by (Abbasi \& Miller, 2013). We can observe that the proposed control chart shows that some points are outside the control limit which is the indication that the process has been shifted. But, the existing control chart indicates that the process is still in control. So, the proposed plan is quite effective in reducing the defective items as compared to the existing control chart because the early detection of the out-of-control process will quickly intimate the quality control personnel to start action for bringing the process back to the in-control condition. In next example, we will compare the efficiency of the proposed control chart over (Abbasi \& Miller, 2013) for the t-distribution.

\section{Example 2}

The proposed repetitive group sampling control chart have also been drawn for the t-distribution for the repetitive sampling (Fig. 8) and the single sampling (Fig. 9) using the simulated data given in table 7. The four control limits have been calculated as $\mathrm{UCL}_{1}=0.970720, \mathrm{UCL}_{2}=0.954121, \mathrm{LCL}_{2}=0.891582, \mathrm{LCL}_{1}=0.874983$. For the purpose of comparison with the single sampling scheme, the control limits UCL $=1.80102$ and LCL $=0.633318$ using the control chart parameters proposed by (Abbasi \& Miller, 2013). We again, see that the proposed control chart is also better than (Abbasi \& Miller, 2013) chart for $t$ distribution case.

Table 7 is around here

Fig. 6-9 are around here

\section{Conclusion}

This paper proposed an EWMA chart based on repetitive group sampling for monitoring the shifts in the process dispersion. A detailed simulation study based on the average run length (ARL), median of run length distribution (MDRL) and the standard deviation of the run length (SDRL) was presented. It has been demonstrated that the EWMA control chart based on repetitive group sampling has competitive edge in the fast detection of shifts in the out-of-control process. The use of proposed chart is recommended for normally and non-normally distributed quality characteristics in the quality control literature.

Table 1 RL characteristics of the EWMA-MD chart under repetitive sampling for normally distributed quality characteristics when $\lambda=0.05$ and ARL0 $=200$. 


\begin{tabular}{|c|c|c|c|c|}
\hline \multirow{2}{*}{\multicolumn{2}{|c|}{$\begin{array}{l}\text { Shift } \\
(\delta)\end{array}$}} & $\mathrm{n}=5$ & $\mathrm{n}=10$ & $\mathrm{n}=15$ \\
\hline & & $\mathrm{k}_{1}=2.325424$ & $\mathrm{k}_{1}=3.73735$, & $\mathrm{k}_{1}=3.259351$ \\
\hline \multirow{5}{*}{1.00} & & $\mathrm{k}_{2}=1.481746$ & $\mathrm{k}_{2}=1.98823$ & $\mathrm{k}_{2}=2.064653$ \\
\hline & ARL1 & 200.00 & 200.00 & 200.00 \\
\hline & MDRL & 39.00 & 22.00 & 21.00 \\
\hline & SDRL & 62.92 & 48.94 & 39.17 \\
\hline & ARL1 & 47.79 & 25.74 & 16.04 \\
\hline \multirow[t]{3}{*}{1.01} & MDRL & 26.00 & 11.00 & 10.00 \\
\hline & SDRL & 55.18 & 35.32 & 33.43 \\
\hline & ARL1 & 35.68 & 15.64 & 13.28 \\
\hline \multirow[t]{3}{*}{1.02} & MDRL & 18.00 & 5.00 & 4.00 \\
\hline & SDRL & 44.46 & 25.20 & 24.11 \\
\hline & ARL1 & 28.53 & 10.69 & 9.32 \\
\hline \multirow[t]{3}{*}{1.03} & MDRL & 11.00 & 2.00 & 2.00 \\
\hline & SDRL & 39.74 & 20.34 & 18.53 \\
\hline & ARL1 & 21.49 & 6.54 & 5.41 \\
\hline \multirow[t]{3}{*}{1.04} & MDRL & 6.50 & 1.00 & 1.00 \\
\hline & SDRL & 33.11 & 14.66 & 12.95 \\
\hline & ARL1 & 14.64 & 3.04 & 2.26 \\
\hline \multirow[t]{3}{*}{1.05} & MDRL & 4.00 & 1.00 & 1.00 \\
\hline & SDRL & 23.83 & 8.76 & 6.17 \\
\hline & ARL1 & 10.69 & 1.80 & 1.31 \\
\hline \multirow[t]{3}{*}{1.06} & MDRL & 2.00 & 1.00 & 1.00 \\
\hline & SDRL & 20.82 & 5.31 & 2.98 \\
\hline & ARL1 & 8.06 & 1.17 & 1.02 \\
\hline \multirow[t]{3}{*}{1.07} & MDRL & 1.00 & 1.00 & 1.00 \\
\hline & SDRL & 17.30 & 1.95 & 0.42 \\
\hline & ARL1 & 4.81 & 1.07 & 1.00 \\
\hline \multirow[t]{3}{*}{1.08} & MDRL & 1.00 & 1.00 & 1.00 \\
\hline & SDRL & 12.08 & 1.10 & 0.06 \\
\hline & ARL1 & 3.43 & 1.00 & 1.00 \\
\hline \multirow[t]{3}{*}{1.09} & MDRL & 1.00 & 1.00 & 1.00 \\
\hline & SDRL & 9.35 & 0.00 & 0.00 \\
\hline & ARL1 & 2.36 & 1.00 & 1.00 \\
\hline \multirow[t]{2}{*}{1.10} & MDRL & 1.00 & 1.00 & 1.00 \\
\hline & SDRL & 6.65 & 0.00 & 0.00 \\
\hline
\end{tabular}

Table 2 RL characteristics of the EWMA-MD chart under repetitive sampling for normally distributed quality characteristics for $\mathrm{n}=5$ and ARL $0=200$.

\begin{tabular}{l|l|l|l|l}
\hline \hline $\begin{array}{l}\text { Shift } \\
(\delta)\end{array}$ & & $\lambda=0.25$ & $\lambda=0.50$ & $\lambda=0.75$ \\
& & $\mathrm{k}_{1}=2.250371$, & $\mathrm{k}_{1}=3.010836$, & $\mathrm{k}_{1}=3.505799$, \\
1.00 & $\mathrm{k}_{2}=2.127114$ & $\mathrm{k}_{2}=2.84386$ & $\mathrm{k}_{2}=2.853409$ \\
& ARL1 & 200.00 & 200.00 & 200.00 \\
1.10 & MDRL & 71.00 & 72.00 & 85.00 \\
& SDRL & 83.36 & 85.85 & 93.28 \\
& ARL1 & 26.15 & 32.26 & 42.85 \\
1.20 & MDRL & 17.00 & 23.50 & 32.00 \\
& SDRL & 25.89 & 31.57 & 39.66 \\
1.30 & ARL1 & 8.95 & 14.12 & 19.81 \\
& MDRL & 6.00 & 10.00 & 14.00 \\
& SDRL & 9.31 & 12.94 & 19.07 \\
\hline & ARL1 & 4.03 & 7.78 & 10.79 \\
\hline
\end{tabular}




\begin{tabular}{|c|c|c|c|c|}
\hline & SDRL & 4.88 & 7.33 & 10.48 \\
\hline & ARL1 & 2.00 & 4.85 & 6.81 \\
\hline \multirow[t]{3}{*}{1.40} & MDRL & 1.00 & 3.00 & 5.00 \\
\hline & SDRL & 2.39 & 5.01 & 6.37 \\
\hline & ARL1 & 1.21 & 3.25 & 4.63 \\
\hline \multirow[t]{3}{*}{1.50} & MDRL & 1.00 & 2.00 & 3.00 \\
\hline & SDRL & 0.96 & 3.23 & 4.17 \\
\hline & ARL1 & 1.04 & 2.34 & 3.43 \\
\hline \multirow[t]{3}{*}{1.60} & MDRL & 1.00 & 1.00 & 2.00 \\
\hline & SDRL & 0.36 & 2.34 & 3.03 \\
\hline & ARL1 & 1.00 & 1.73 & 2.90 \\
\hline \multirow[t]{3}{*}{1.70} & MDRL & 1.00 & 1.00 & 2.00 \\
\hline & SDRL & 0.06 & 1.54 & 2.67 \\
\hline & ARL1 & 1.00 & 1.50 & 2.30 \\
\hline \multirow[t]{3}{*}{1.80} & MDRL & 1.00 & 1.00 & 2.00 \\
\hline & SDRL & 0.00 & 1.16 & 1.85 \\
\hline & ARL1 & 1.00 & 1.32 & 1.95 \\
\hline \multirow[t]{3}{*}{1.90} & MDRL & 1.00 & 1.00 & 1.00 \\
\hline & SDRL & 0.00 & 0.83 & 1.54 \\
\hline & ARL1 & 1.00 & 1.19 & 1.77 \\
\hline \multirow[t]{2}{*}{2.00} & MDRL & 1.00 & 1.00 & 1.00 \\
\hline & SDRL & 0.00 & 0.61 & 1.28 \\
\hline
\end{tabular}

Table 3 RL characteristics of the EWMA-MD chart under repetitive sampling for t-distributed quality characteristics when $\lambda$ $=0.05$ and ARL0 $=200$.

\begin{tabular}{l|l|l|l|l}
\hline \hline \multicolumn{1}{|c|}{$\begin{array}{l}\text { Shift } \\
(\delta)\end{array}$} & $\mathrm{n}=5$ & $\mathrm{n}=10$ & $\mathrm{n}=15$ \\
& & $\mathrm{k}_{1}=2.248201$, & $\mathrm{k}_{1}=2.234471$, & $\mathrm{k}_{1}=2.633052$, \\
1.00 & $\mathrm{k}_{2}=1.468618$ & $\mathrm{k}_{2}=1.366732$ & $\mathrm{k}_{2}=1.514487$ \\
& ARL1 & 200.00 & 200.00 & 200.00 \\
1.01 & MDRL & 39.00 & 22.00 & 21.00 \\
& SDRL & 62.92 & 48.94 & 39.17 \\
& ARL1 & 47.79 & 25.74 & 16.04 \\
1.02 & MDRL & 26.00 & 11.00 & 10.00 \\
& SDRL & 55.18 & 35.32 & 33.43 \\
1.03 & ARL1 & 35.68 & 15.64 & 13.28 \\
& MDRL & 18.00 & 5.00 & 4.00 \\
& SDRL & 44.46 & 25.20 & 24.11 \\
& ARL1 & 28.53 & 10.69 & 9.32 \\
& MDRL & 11.00 & 2.00 & 2.00 \\
\hline
\end{tabular}




\begin{tabular}{|c|c|c|c|c|}
\hline & SDRL & 39.74 & 20.34 & 18.53 \\
\hline & ARL1 & 21.49 & 6.54 & 5.41 \\
\hline \multirow[t]{3}{*}{1.04} & MDRL & 6.50 & 1.00 & 1.00 \\
\hline & SDRL & 33.11 & 14.66 & 12.95 \\
\hline & ARL1 & 14.64 & 3.04 & 2.26 \\
\hline \multirow[t]{3}{*}{1.05} & MDRL & 4.00 & 1.00 & 1.00 \\
\hline & SDRL & 23.83 & 8.76 & 6.17 \\
\hline & ARL1 & 10.69 & 1.80 & 1.31 \\
\hline \multirow[t]{3}{*}{1.06} & MDRL & 2.00 & 1.00 & 1.00 \\
\hline & SDRL & 20.82 & 5.31 & 2.98 \\
\hline & ARL1 & 8.06 & 1.17 & 1.02 \\
\hline \multirow[t]{3}{*}{1.07} & MDRL & 1.00 & 1.00 & 1.00 \\
\hline & SDRL & 17.30 & 1.95 & 0.42 \\
\hline & ARL1 & 4.81 & 1.07 & 1.00 \\
\hline \multirow[t]{3}{*}{1.08} & MDRL & 1.00 & 1.00 & 1.00 \\
\hline & SDRL & 12.08 & 1.10 & 0.06 \\
\hline & ARL1 & 3.43 & 1.00 & 1.00 \\
\hline \multirow[t]{3}{*}{1.09} & MDRL & 1.00 & 1.00 & 1.00 \\
\hline & SDRL & 9.35 & 0.00 & 0.00 \\
\hline & ARL1 & 2.36 & 1.00 & 1.00 \\
\hline \multirow[t]{2}{*}{1.10} & MDRL & 1.00 & 1.00 & 1.00 \\
\hline & SDRL & 6.65 & 0.00 & 0.00 \\
\hline
\end{tabular}

Table 4 RL characteristics of the EWMA-MD chart under repetitive sampling for t-distributed quality characteristics for $\mathrm{n}$ $=5$ and ARL $0=200$.

\begin{tabular}{|c|c|c|c|c|}
\hline \multicolumn{2}{|l|}{ Shift } & $\lambda=0.25$ & $\lambda=0.50$ & $\lambda=0.75$ \\
\hline \multirow[t]{3}{*}{$(\delta)$} & & $\mathrm{k}_{1}=3.334963$, & $\mathrm{k}_{1}=3.655528$, & $\mathrm{k}_{1}=3.745567$ \\
\hline & & $\mathrm{k}_{2}=2.464435$ & $\mathrm{k}_{2}=2.599459$ & $\mathrm{k}_{2}=2.712584$ \\
\hline & ARL1 & 201.00 & 200.00 & 201.00 \\
\hline \multirow[t]{3}{*}{1.00} & MDRL & 63.00 & 67.50 & 85.00 \\
\hline & SDRL & 75.74 & 79.73 & 89.24 \\
\hline & ARL1 & 23.44 & 30.23 & 40.21 \\
\hline \multirow[t]{3}{*}{1.10} & MDRL & 16.00 & 20.00 & 28.00 \\
\hline & SDRL & 23.33 & 30.70 & 40.66 \\
\hline & ARL1 & 8.93 & 13.45 & 18.75 \\
\hline \multirow[t]{3}{*}{1.20} & MDRL & 5.00 & 10.00 & 13.00 \\
\hline & SDRL & 9.73 & 12.38 & 18.18 \\
\hline & ARL1 & 3.83 & 7.26 & 9.82 \\
\hline \multirow[t]{2}{*}{1.30} & MDRL & 2.00 & 5.00 & 7.00 \\
\hline & SDRL & 4.73 & 7.32 & 9.67 \\
\hline
\end{tabular}




\begin{tabular}{|c|c|c|c|c|}
\hline \multirow{3}{*}{1.40} & ARL1 & 1.85 & 4.40 & 6.69 \\
\hline & MDRL & 1.00 & 3.00 & 5.00 \\
\hline & SDRL & 2.23 & 4.38 & 6.30 \\
\hline \multirow{3}{*}{1.50} & ARL1 & 1.22 & 3.08 & 4.55 \\
\hline & MDRL & 1.00 & 2.00 & 3.00 \\
\hline & SDRL & 0.99 & 3.08 & 3.98 \\
\hline \multirow{3}{*}{1.60} & ARL1 & 1.03 & 2.22 & 3.52 \\
\hline & MDRL & 1.00 & 1.00 & 2.00 \\
\hline & SDRL & 0.28 & 2.04 & 3.09 \\
\hline \multirow{3}{*}{1.70} & ARL1 & 1.00 & 1.77 & 2.76 \\
\hline & MDRL & 1.00 & 1.00 & 2.00 \\
\hline & SDRL & 0.00 & 1.65 & 2.29 \\
\hline \multirow{3}{*}{1.80} & ARL1 & 1.00 & 1.44 & 2.27 \\
\hline & MDRL & 1.00 & 1.00 & 2.00 \\
\hline & SDRL & 0.00 & 1.02 & 1.88 \\
\hline \multirow{3}{*}{1.90} & ARL1 & 1.00 & 1.25 & 1.94 \\
\hline & MDRL & 1.00 & 1.00 & 1.00 \\
\hline & SDRL & 0.00 & 0.75 & 1.43 \\
\hline \multirow{3}{*}{2.00} & ARL1 & 1.00 & 1.17 & 1.73 \\
\hline & MDRL & 1.00 & 1.00 & 1.00 \\
\hline & SDRL & 0.00 & 0.64 & 1.21 \\
\hline
\end{tabular}

Table $5 \mathrm{RL}$ characteristics of the EWMA-MD chart under repetitive sampling for Gamma distributed quality characteristics when $\lambda=0.05$ and ARL0 $=200$.

\begin{tabular}{l|l|l|l|l}
\hline \hline $\begin{array}{l}\text { Shift } \\
(\delta)\end{array}$ & & $\mathrm{n}=5$ & $\mathrm{n}=10$ & $\mathrm{n}=15$ \\
& & $\mathrm{k}_{1}=2.58425$, & $\mathrm{k}_{1}=2.881411$, & $\mathrm{k}_{1}=2.940985$, \\
1.00 & ARL1 & $\mathrm{k}_{2}=2.482192$ & $\mathrm{k}_{2}=2.550056$ & $\mathrm{k}_{2}=1.847446$ \\
& MDRL & 158.00 & 200.00 & 201.00 \\
1.01 & SDRL & 100.10 & 145.40 & 133.53 \\
& ARL1 & 48.76 & 75.74 & 53.47 \\
& MDRL & 55.50 & 22.38 & 8.95 \\
1.02 & SDRL & 107.32 & 24.00 & 11.00 \\
& ARL1 & 45.01 & 75.32 & 46.22 \\
& MDRL & 44.00 & 20.45 & 9.42 \\
1.03 & SDRL & 103.70 & 21.00 & 10.00 \\
& ARL1 & 43.33 & 71.87 & 48.12 \\
& MDRL & 42.50 & 14.52 & 7.37 \\
& SDRL & 101.94 & 13.00 & 6.00 \\
\hline
\end{tabular}




\begin{tabular}{l|l|l|l|l}
\hline \hline \multirow{3}{*}{1.04} & ARL1 & 39.42 & 11.90 & 6.61 \\
& MDRL & 31.00 & 10.00 & 7.00 \\
1.05 & SDRL & 97.62 & 66.50 & 39.46 \\
& ARL1 & 35.05 & 10.39 & 5.86 \\
& MDRL & 30.00 & 9.00 & 6.00 \\
1.06 & SDRL & 92.26 & 66.64 & 49.22 \\
& ARL1 & 30.81 & 8.52 & 7.23 \\
1.07 & MDRL & 26.00 & 6.00 & 5.00 \\
& SDRL & 94.23 & 71.63 & 44.50 \\
1.08 & ARL1 & 27.74 & 6.67 & 5.58 \\
& MDRL & 21.00 & 3.00 & 1.00 \\
1.09 & SDRL & 85.44 & 55.40 & 42.49 \\
& ARL1 & 23.83 & 5.45 & 4.02 \\
& MDRL & 11.50 & 1.00 & 1.00 \\
1.10 & SDRL & 25.93 & 6.27 & 7.34 \\
& ARL1 & 20.88 & 4.69 & 3.02 \\
& MDRL & 1.00 & 1.00 & 1.00 \\
& SDRL & 14.00 & 0.00 & 0.00 \\
& ARL1 & 18.88 & 3.27 & 1.32 \\
& MDRL & 1.00 & 1.00 & 1.00 \\
& SDRL & 8.82 & 0.00 & 0.00 \\
\hline
\end{tabular}

Table $6 \mathrm{RL}$ characteristics comparison of the proposed Vs the existing EWMA-MD chart under repetitive sampling for Gamma distributed quality characteristics when $\lambda=0.05$ and ARL $0=200$.

\begin{tabular}{c|l|l|l|l|l|l|l}
\hline \hline Shift & & $\mathrm{n}=5$ & & $\mathrm{n}=10$ & & $\mathrm{n}=15$ & \\
1.0 & $(\delta)$ & existing & proposed & existing & proposed & existing & proposed \\
1.0 & ARL1 & 200.01 & 201.00 & 199.07 & 200.00 & 199.71 & 201.00 \\
& MDRL & 138.00 & 158.02 & 138.00 & 145.40 & 142.00 & 133.53 \\
1.1 & SDRL & 206.32 & 100.10 & 196.97 & 75.74 & 192.92 & 53.47 \\
& ARL1 & 44.74 & 18.88 & 28.58 & 3.27 & 22.40 & 1.32 \\
& MDRL & 34.00 & 1.00 & 23.00 & 1.00 & 18.00 & 1.00 \\
& SDRL & 38.41 & 8.82 & 21.33 & 0.00 & 15.63 & 0.00 \\
\hline
\end{tabular}


Table 7 Simulated data from $\mathrm{t}$-distribution using $\mathrm{n}=5$

\begin{tabular}{|c|c|c|c|c|c|}
\hline Sample No & $\mathrm{x}_{1}$ & $\mathrm{x}_{2}$ & $\mathrm{x}_{3}$ & $\mathrm{x}_{4}$ & $x_{5}$ \\
\hline 1 & -0.864213 & -0.075916 & 0.282955 & -1.246167 & -0.867957 \\
\hline 2 & -0.968176 & -0.122591 & 0.326920 & 1.385271 & 2.781178 \\
\hline 3 & -1.695010 & -2.034331 & 2.668442 & 0.006167 & -1.065142 \\
\hline 4 & -1.500314 & 0.727061 & 0.316451 & -1.405659 & 0.913869 \\
\hline 5 & 1.219042 & -1.715757 & -0.888560 & 1.888311 & 1.566977 \\
\hline 6 & -1.562660 & -0.653608 & 0.241496 & 1.737001 & -1.831075 \\
\hline 7 & 0.277477 & 0.715265 & -2.237121 & -1.209037 & -0.117330 \\
\hline 8 & 1.763570 & -0.486522 & -1.196184 & -0.265939 & 0.895675 \\
\hline 9 & -0.293001 & -0.127555 & 2.865115 & 0.627277 & 0.710417 \\
\hline 10 & 1.515023 & -0.411253 & -1.398561 & 0.464651 & 0.084530 \\
\hline 11 & 1.070757 & -2.460861 & -1.915761 & 0.605462 & -0.101068 \\
\hline 12 & -0.722705 & -2.033324 & -1.029773 & -0.827874 & 1.733670 \\
\hline 13 & -0.918541 & 0.994505 & -0.342864 & -0.883110 & 2.413542 \\
\hline 14 & -0.407914 & -0.857811 & 0.233745 & 0.629990 & 1.260753 \\
\hline 15 & 1.222497 & -1.286503 & -0.035588 & 1.285791 & 0.678109 \\
\hline 16 & -0.189630 & 0.297215 & -1.234035 & 1.670774 & -2.134588 \\
\hline 17 & -1.606057 & -2.628303 & -2.683552 & 0.913874 & -0.336226 \\
\hline 18 & -0.898280 & -3.054140 & 1.404873 & -0.704456 & 1.512026 \\
\hline 19 & 0.241830 & -1.330917 & -2.211682 & 1.580123 & 0.508627 \\
\hline 20 & 1.216767 & 2.284648 & -0.634834 & -1.363537 & 0.196709 \\
\hline 21 & 0.810108 & 0.477196 & -2.501139 & -0.216359 & 0.344165 \\
\hline 22 & 1.750524 & 0.672026 & -0.395894 & 0.548495 & 0.316691 \\
\hline 23 & 0.453202 & 0.537166 & 0.033679 & 0.043997 & -0.910044 \\
\hline 24 & 2.863079 & -0.565897 & -0.086182 & -0.488367 & -0.662202 \\
\hline 25 & -0.004601 & -2.585260 & -0.638246 & -0.865314 & -0.940544 \\
\hline
\end{tabular}

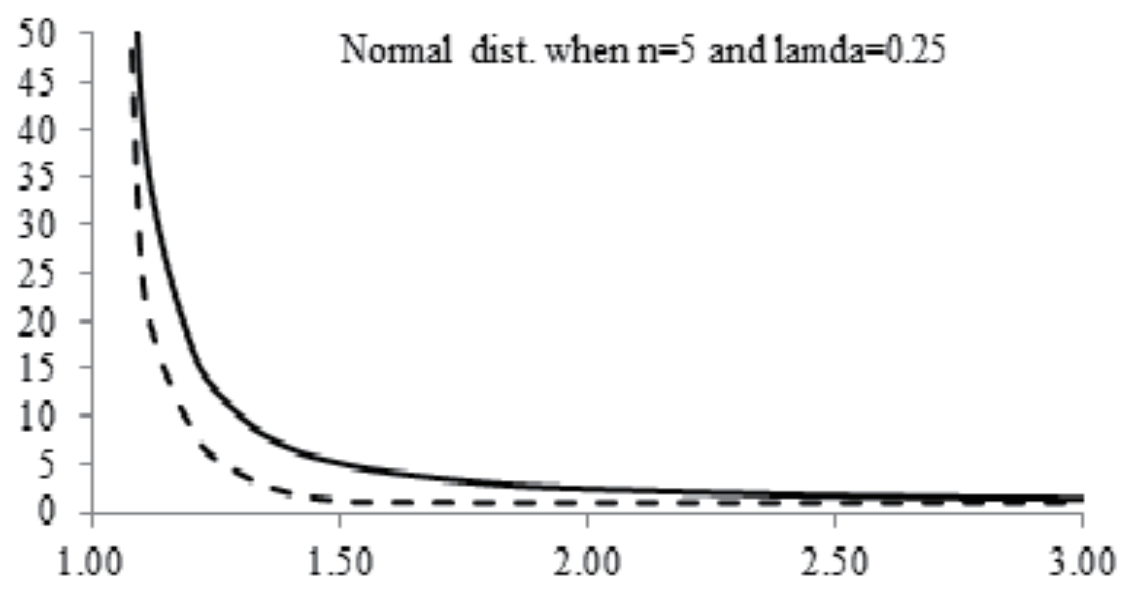


Fig. $1 \mathrm{ARL}_{1}$ for the proposed and existing chart for normal dist. for $\mathrm{n}=5$ and $\lambda=0.25$

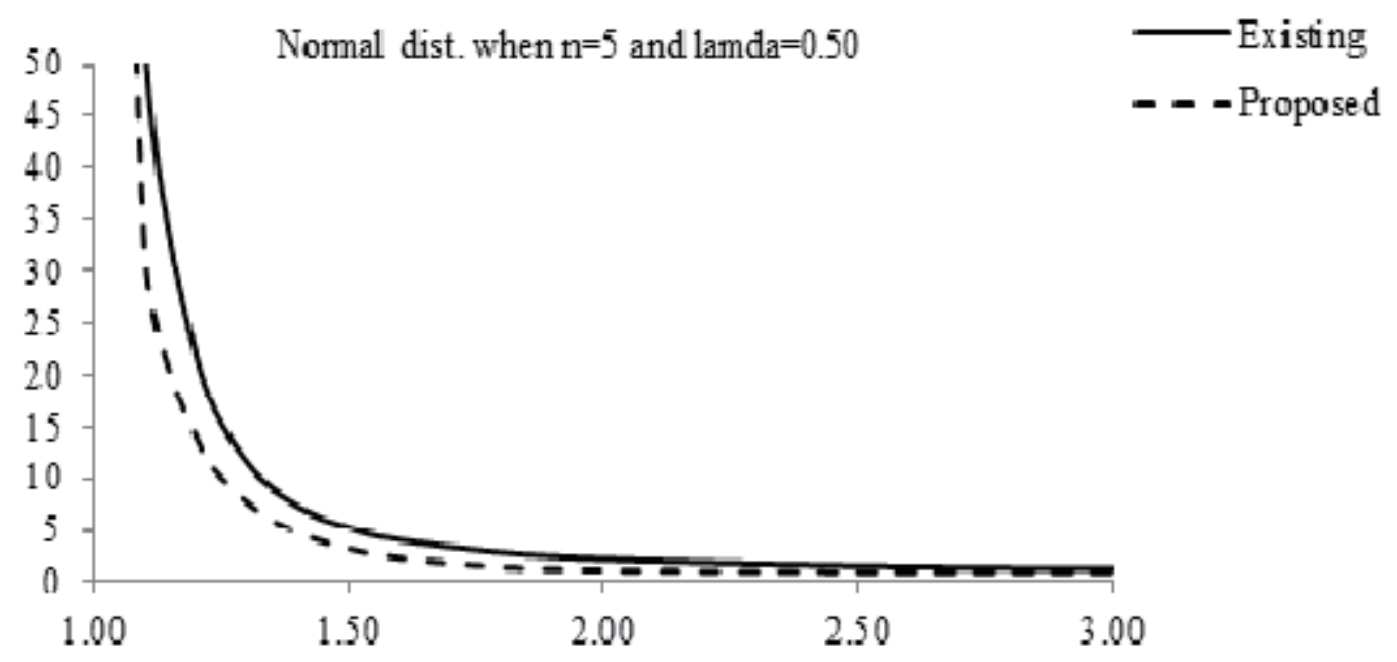

Fig. 2 ARL1 for the proposed and existing chart for normal dist. for $n=5$ and $\lambda=0.50$

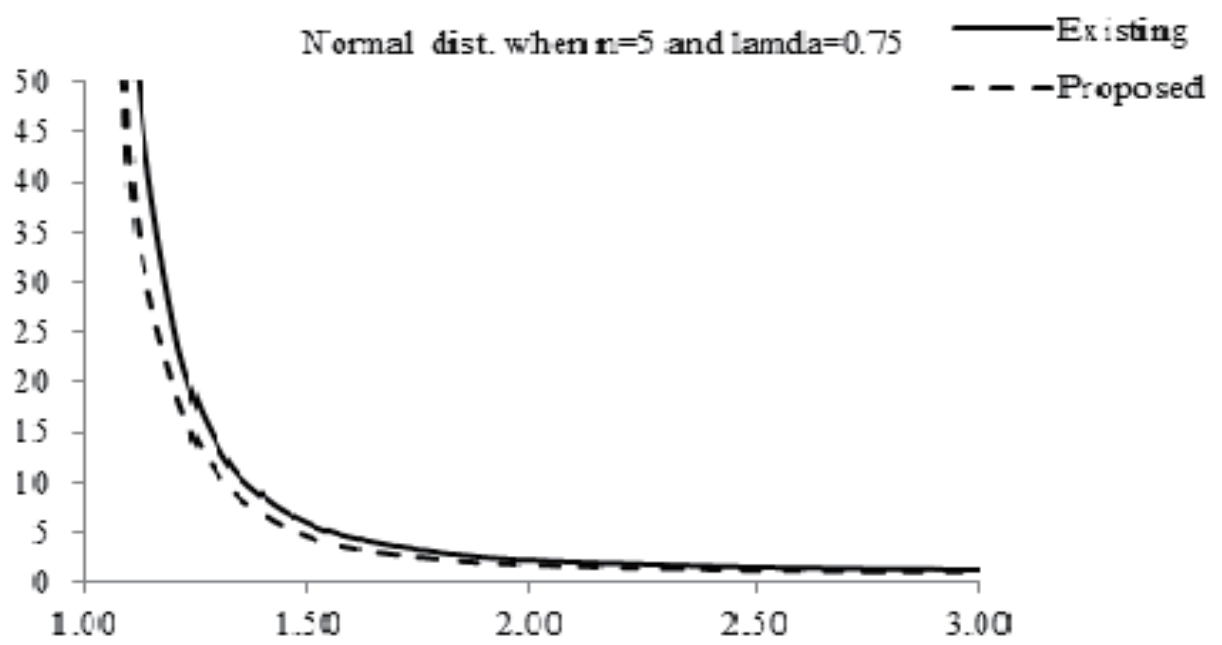

Fig. $3 \mathrm{ARL}_{1}$ for the proposed and existing chart for normal dist. for $\mathrm{n}=5$ and $\lambda=0.75$ 


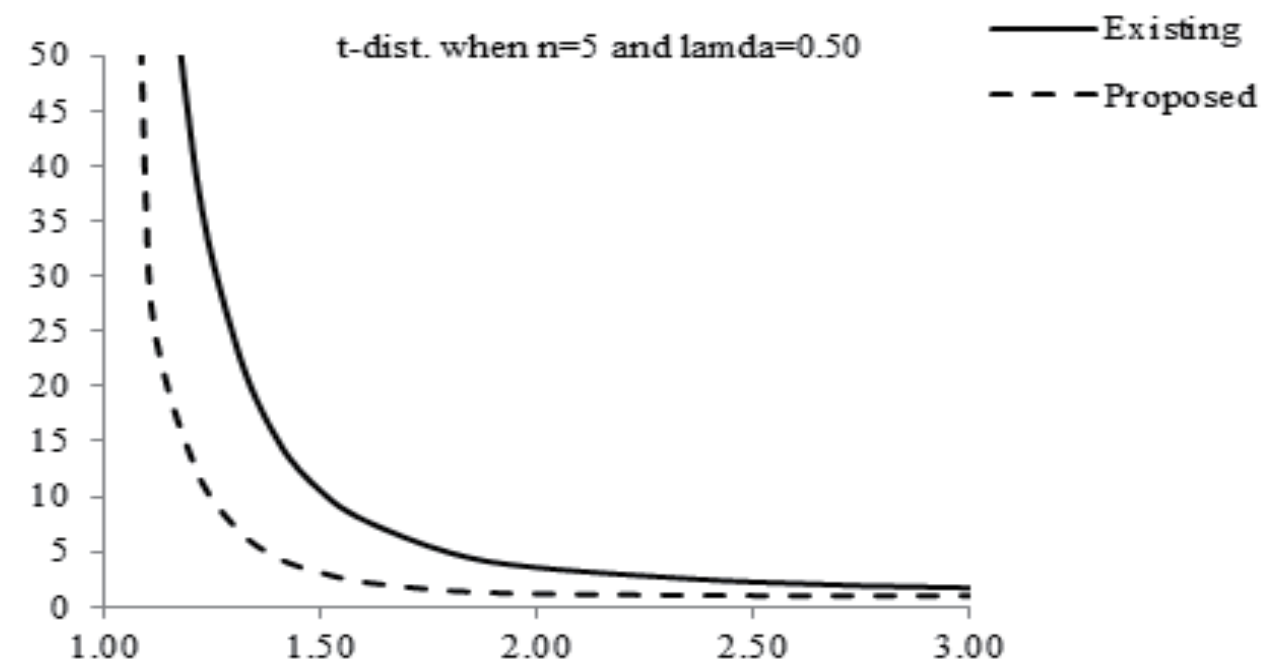

Fig. $4 \mathrm{ARL}_{1}$ for the proposed and existing chart for $\mathrm{t}$-dist. for $\mathrm{n}=5$ and $\lambda=0.50$

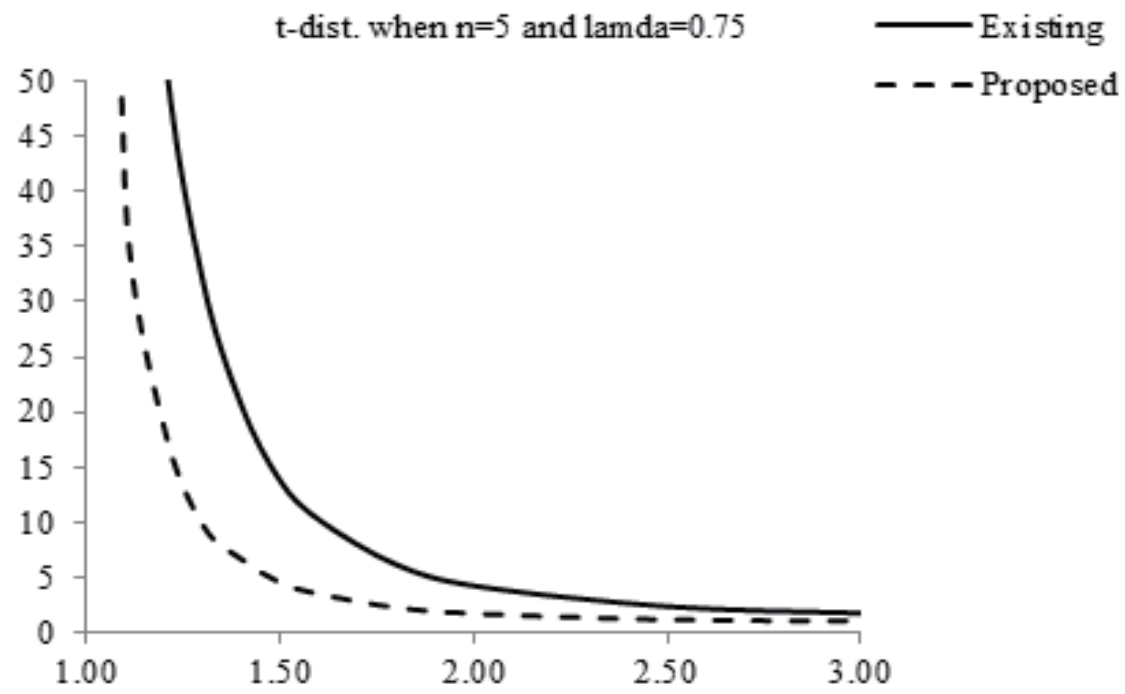

Fig. $5 \mathrm{ARL}_{1}$ for the proposed and existing chart for $\mathrm{t}$-dist. for $\mathrm{n}=5$ and $\lambda=0.75$ 
Repetitive Sampling Control Chart for Wt Using Normal Distribution

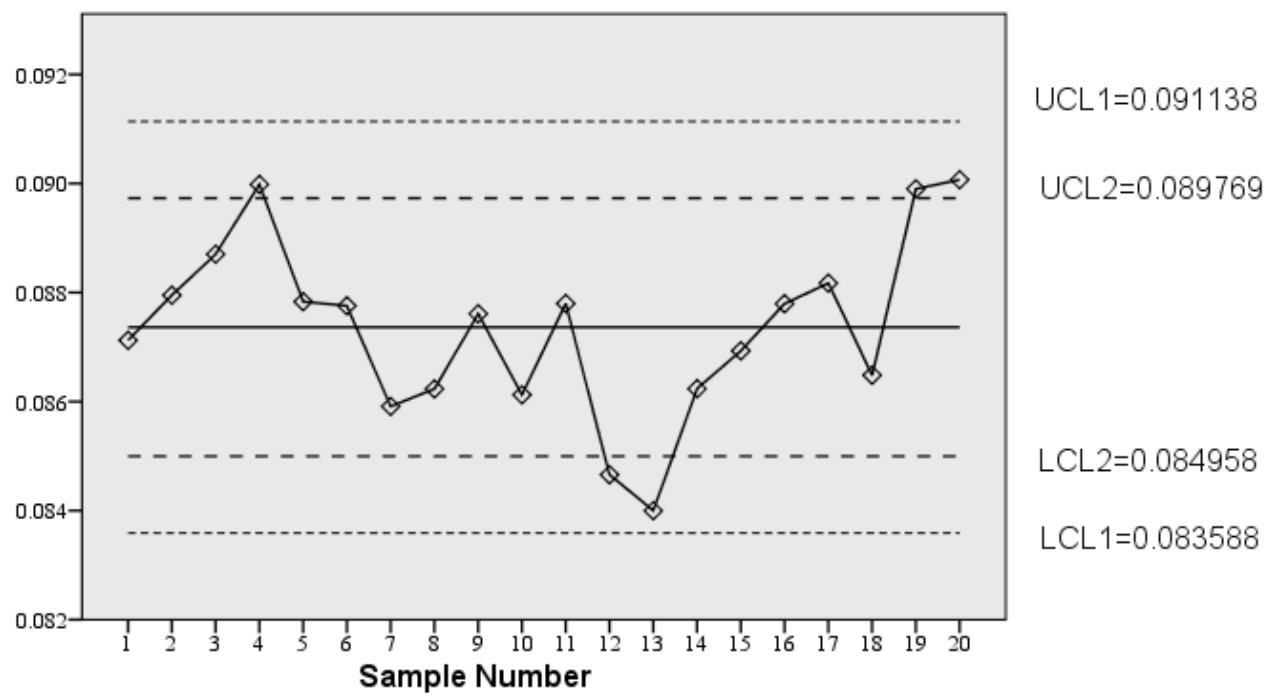

Fig. 6 Control chart of repetitive sampling for $n=5$ and $\lambda=0.05$ under the normal distribution

\section{Single Sampling Control Chart For Wt Using Normal Distribution}

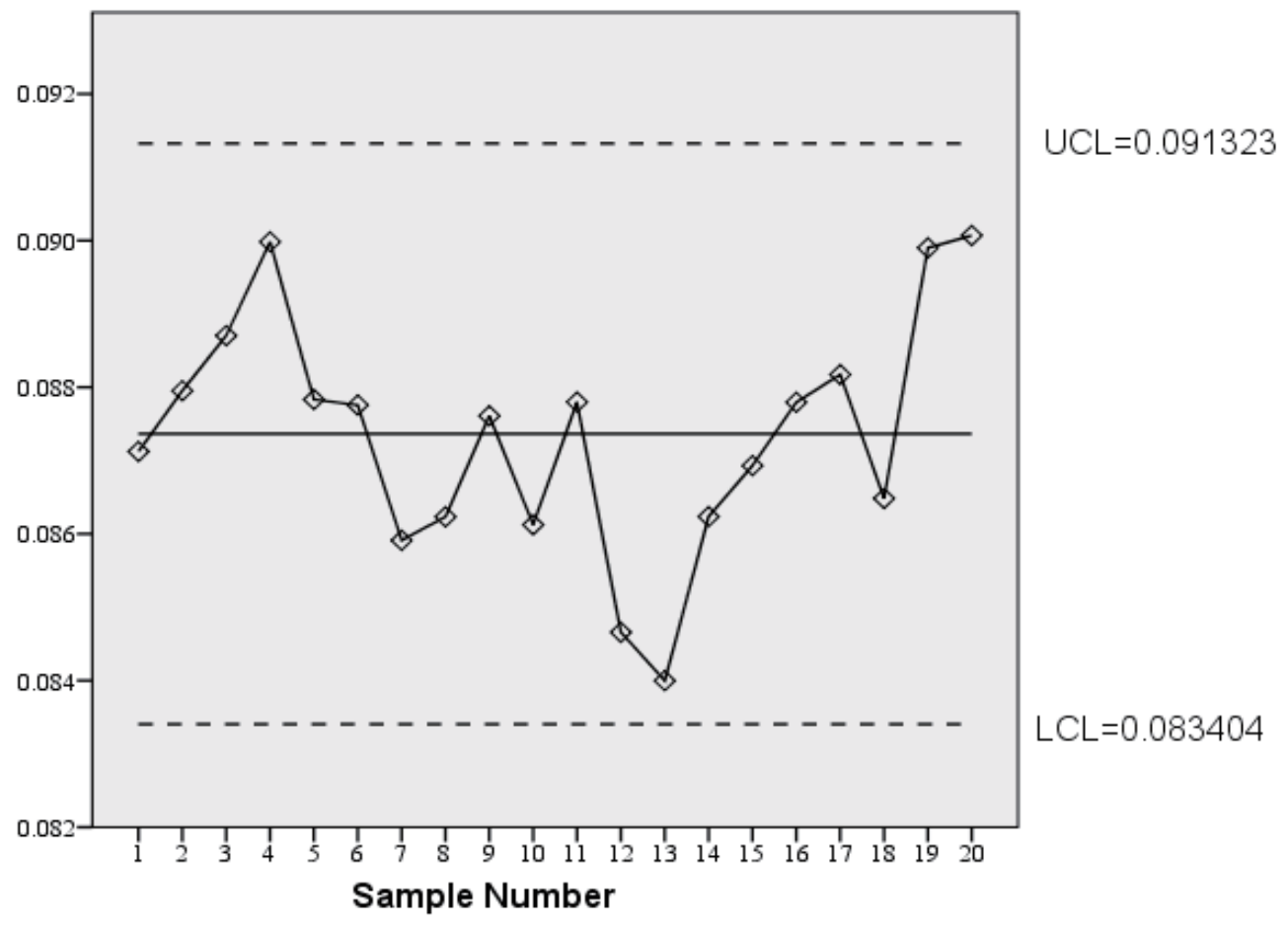

Fig. 7 Control chart of single sampling for $n=5$ and $\lambda=0.05$ under the normal distribution 


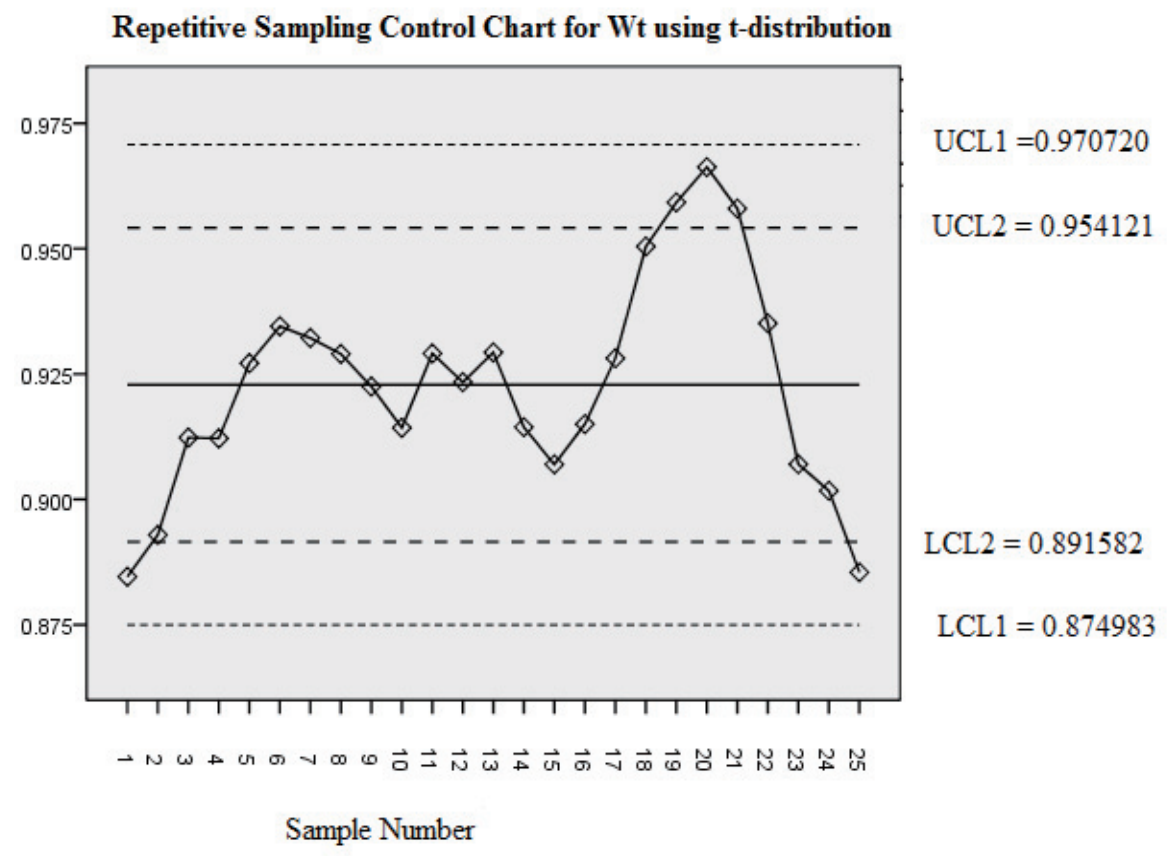

Fig. 8 Control chart of repetitive group sampling for $\mathrm{n}=5$ and $\lambda=0.05$ under the $\mathrm{t}$ - distribution

Single Sampling Control Chart for Wt Using t-distribution

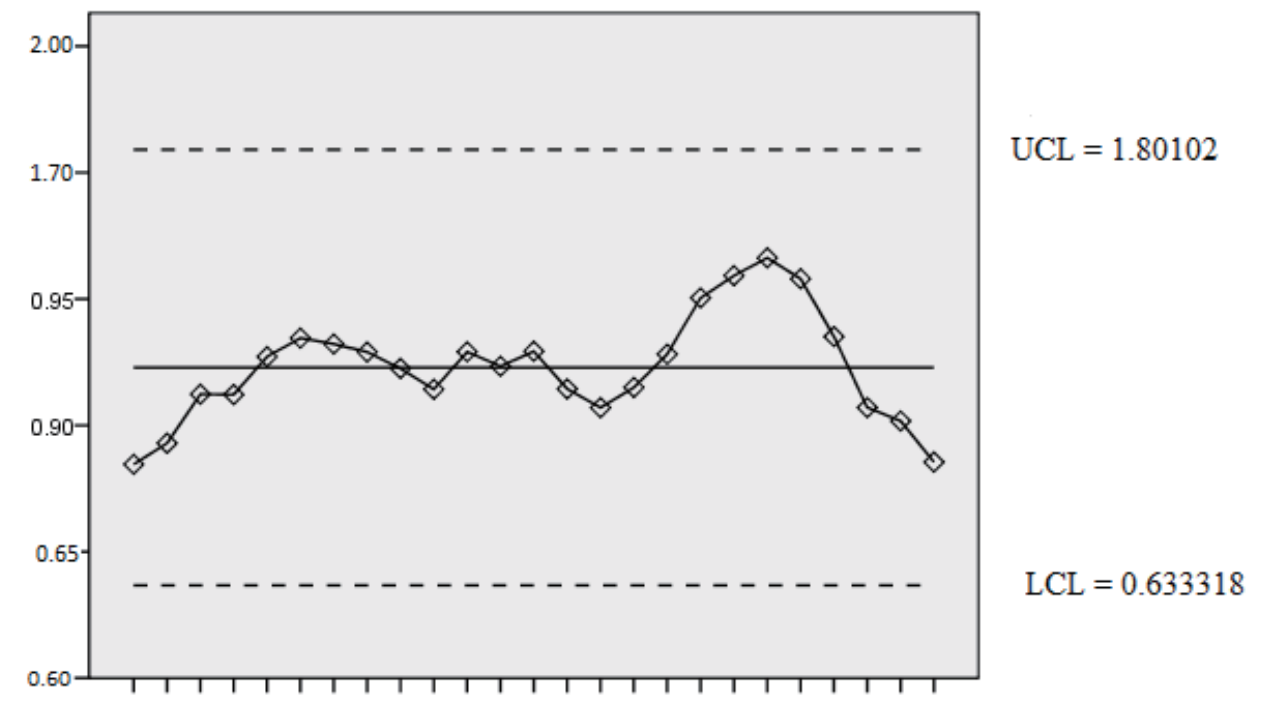

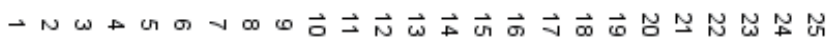

Sample Number

Fig. 9 Control chart of single sampling for $n=5$ and $\lambda=0.05$ under the $t$ - distribution

\section{Acknowledgements}

The authors are deeply thankful to editor and two reviewers for their valuable suggestions to improve the quality of this manuscript. This article was funded by the Deanship of Scientific Research (DSR), King Abdulaziz University, Jeddah. The authors, Muhammad Aslam and Osama H. Arif, therefore, acknowledge with thanks DSR technical and financial support. 


\section{References}

Abbasi, S. A., On the Performance of EWMA Chart in the Presence of Two-Component Measurement Error, Quality Engineering, Vol.22, No.3 (2010), pp.199-213.

Abbasi, S. A. and Miller, A., MDEWMA chart: an efficient and robust alternative to monitor process dispersion, Journal of Statistical Computation and Simulation, Vol.83, No.2 (2013), pp.247-268.

Abujiya, M. A. R., Lee, M. H. and Riaz, M., Improving the Performance of Exponentially Weighted Moving Average Control Charts, Quality and Reliability Engineering International, Vol.30, No.4 (2014), pp.571-590.

Ahmad, L., Aslam, M. and Jun, C. H., Coal Quality Monitoring With Improved Control Charts, European Journal of Scientific Research, Vol.125, No.2 (2014a), pp.427-434.

Ahmad, L., Aslam, M. and Jun, C. H., Designing of X-bar control charts based on process capability index using repetitive sampling, Transactions of the Institute of Measurement and Control, Vol.36, No.3 (2014b), pp.367-374.

Aslam, M., Niaki, S. T. A., Rasool, M. and Fallahnezhad, M. S., Decision rule of repetitive acceptance sampling plans assuring percentile life, Scientia Iranica.Transaction E, Industrial Engineering Vol.19, No.3 (2012), pp.879.

Aslam, M., Yen, C. H. and Jun, C. H., Variable repetitive group sampling plans with process loss consideration, Journal of Statistical Computation and Simulation, Vol.81, No.11 (2011), pp.1417-1432.

Balamurali, S. and Jun, C. H., Repetitive Group Sampling Procedure for Variables Inspection, Journal of Applied Statistics, Vol.33, No.3 (2006), pp.327-338.

Balamurali, S., Park, H., Jun, C. H., Kim, K. J. and Lee, J., Designing of Variables Repetitive Group Sampling Plan Involving Minimum Average Sample Number, Communications in Statistics-Simulation and Computation, Vol.34, No.3 (2005), pp.799-809.

Barnard, G. A., Control charts and stochastic processes, Journal of the Royal Statistical Society. Series B (Methodological), (1959), pp.239-271.

Bissell, A., Cusum techniques for quality control, Applied Statistics, Vol.18 (1969), pp.1-30.

Borror, C. M., Montgomery, D. C. and Runger, G. C., Robustness of the EWMA control chart to non-normality, Journal of Quality Technology, Vol.31, No.3 (1999), pp.309.

Chan, L. K. and Zhang, J., Some issues in the design of EWMA Charts, Communications in Statistics - Simulation and Computation, Vol.29, No.1 (2000), pp.201-217.

Eddington, A. S., Stellar Movements and the Structure of the Universe (1914), Macmillan and Company, limited.

Fallah Nezhad, M., A new EWMA monitoring design for multivariate quality control problem, The International Journal of Advanced Manufacturing Technology, Vol.62, No.5-8 (2012), pp.751-758.

G, S. Z. and H, S. J., Robustness to non-normality of the multivariate EWMA control chart, Journal of Quality Technology, Vol.34, No.3 (2002), pp.260-276.

Gan, F., An optimal design of cumulative sum control chart based on median run length, Communications in Statistics-Simulation and Computation, Vol.23, No.2 (1994), pp.485-503.

Gan, F. F., An optimal design of ewma control charts based on median run length, Journal of Statistical Computation and Simulation, Vol.45, No.3-4 (1993), pp.169-184.

Gorard, S., Revisiting a 90-year-old debate: the advantages of the mean deviation (2004), University of Manchester.

Kane, V. E., Process Capability Indices, Journal of Quality Technology, Vol.18, No.1 (1986), pp.41-52.

Leys, C., Ley, C., Klein, O., Bernard, P. and Licata, L., Detecting outliers: Do not use standard deviation around the mean, use absolute deviation around the median, Journal of Experimental Social Psychology, Vol.49, No.4 (2013), pp.764-766.

Maravelakis, P. E., Panaretos, J. and Psarakis, S., An Examination of the Robustness to Non Normality of the EWMA Control Charts for the Dispersion, Communications in Statistics - Simulation and Computation, Vol.34, No.4 (2005), pp.1069-1079.

Montgomery, D. C., Introduction to Statistical Quality Control (2009), (6th ed.). New York: John Wiley \& Sons, Inc.

Page, E. S., Continuous Inspection Schemes, Biometrika, Vol.41, (1954), pp.100-115.

Park, H.-K., Moon, Y.-G., Jun, C.-H., Balamurali, S. and Lee, J.-W., A variables repetitive group sampling plan for minimizing average sample number, Journal of Korean Institute of Industrial Engineers, Vol.30, No.3 (2004), pp.205-212.

Riaz, M. and Saghir, A., A mean deviation-based approach to monitor process variability, Journal of Statistical Computation and Simulation, Vol.79, No.10 (2009), pp.1173-1193. 
Roberts, S. W., Control Chart Tests Based on Geometric Moving Averages, Technometrics, Vol.1, No.3 (1959), pp.239-250.

Robinson, P. B. and Ho, T. Y., Average Run Lengths of Geometric Moving Charts by Numerical Methods, Technometrics, Vol.20, No.1 (1978), pp.85-93.

Shamsuzzaman, M., Khoo, M. B. C., Haridy, S. and Alsyouf, I., An optimization design of the 3-EWMA scheme for monitoring mean shifts, The International Journal of Advanced Manufacturing Technology, Vol.74, No.5-8 (2014), pp.1061-1076.

Sherman, R. E., Design and Evaluation of a Repetitive Group Sampling Plan, Technometrics, Vol.7, No.1 (1965), pp.11-21.

Shewhart, W. A., Quality Control Charts, Bell System Technical Journal, Vol.5, No.4 (1926), pp.593-603.

Srivastava, M. S. and Wu, Y., Comparison of EWMA, CUSUM and Shiryayev-Roberts Procedures for Detecting a Shift in the Mean, The Annals of Statistics, Vol.21, No.2 (1993), pp.645-670.

Stoumbos, Z. G. and Sullivan, J. H., Robustness to Non-normality of the Multivariate EWMA Control Chart, Journal of Quality Technology, Vol.34, No.3 (2002), pp.260-276.

Stoumbos, Z. G. and Reynolds, M. R., Robustness to non-normality and autocorrelation of individuals control charts, Journal of Statistical Computation and Simulation, Vol.66, No.2 (2000), pp.145-187.

Testik, M. C., Runger, G. C. and Borror, C. M., Robustness properties of multivariate EWMA control charts, Quality and Reliability Engineering International, Vol.19, No.1 (2003), pp.31-38.

Tukey, J., A Survey of Sampling From Contaminated Distributions, Contributions to Probability and Statistics: Volume Dedicated to Harold Hetelling (1960), Stanford, CA: Stanford University Press.

Woodall, W. H., The distribution of the run length of one-sided CUSUM procedures for continuous random variables, Technometrics, Vol.25, No.3 (1983), pp.295-301. 